DOI : $10.14746 /$ ps.2019.1.29

\title{
Perceptions of China's Role in the MENA Region, The 5th China and the Middle East and North Africa Conference, Shanghai, 17-18 May, 2019
}

China's foreign policy is an issue of interest to researchers representing various disciplines, including political and security sciences, international studies, law as well as journalism and communication. Therefore, it is not surprising that a number of scientific conferences devoted to Beijing's relations with individual geopolitical regions and actors on the international arena is constantly growing. Most of them focus on both China's relations with the United States, Russia, or the European Union, and strategic conflicts, e.g. in the South China Sea. By contrast, there are also events that aim to explore new directions in China's foreign policy. The 5th China and the Middle East and North Africa Conference organized on May 17-18, 2019, at Shanghai University (SHU), can serve as an example of an interdisciplinary event related to Beijing's role in one of the key regions for the world's stability: MENA.

This year's edition of the Conference was organized by the units of Shanghai University: Institute of Global Studies, Center for Turkish Studies and College of Liberal Arts. The formula for selecting a host of the event is based on multi-institutional collaboration. Previous editions were hosted by Peking University (March 17-18, 2015), Qatar University (March 23-24, 2016), Shanghai University (June 7-8, 2017), Nevsehir Haci Bektas Veli University and Cappadocia University (June 20-22, 2018) (Call for papers) respectively. Conscious of the growing role of the Middle East and North Africa in China's foreign policy agenda, organizers of the Conference welcomed submissions related to numerous issues, both general and specific, including political economy of the Middle East, nationalism and nation-state, political parties, environment, social movements, religion and politics, gender, energy, trade, economic integration, Israeli-Palestinian conflict, modern Middle East and modern China, China's foreign policy toward Middle East/West Asia, and the Belt and Road Initiative (Call for papers). The main organizers of the Conference, Dr. Tugrul Keskin (Director of Center for Global Governance, SHU) and Dr. Yang Chen (Director of Center for Turkish Studies, SHU), were supported by the Organizing Committee consisting of respected scholars representing academic institutions from Canada, China, Israel, Iran, Pakistan, Qatar, Turkey, and the United States (Call for papers).

Held in the New Le Hu Hotel (Baoshan Campus, Shanghai University), the Conference was officially opened by Dr. Tugrul Keskin. During the inaugural panel moderated by Prof. Guo Changgang (Shanghai University), the welcome speech was delivered by Prof. Yang Guang from Chinese Academy of Social Sciences. It was followed by the keynote speech dedicated to the foreign policy of Donald Trump's administration towards the MENA region presented by Prof. Juan Cole from the University of Michigan, former President of the Middle East Studies Association of North America.

The first day of the Conference proceedings consisted of six panels and was divided into three parallel panel sessions. Before lunch the listeners could enjoy papers related to the perceptions of China's soft power in the UAE, China's projections in North Africa, the Belt and Road Initiative (BRI) from the perspective of the theory of international relations, and Syrian men's disability in the context of displacement in Jordan (panel 2). By 
contrast, panel 3 encompassed speeches devoted to Turkey and the Gulf in terms of the political-economic challenges of an unstable region, the role of Saudi Arabia in relations between Saudi Arabia and China, female religious activity, and BRI in expanding Beijing's ties with West Asia and North Africa. Some of the most interesting papers from the following panels included: "The 'Quandary of Made in China': Palestinian Globalisation from Below Under Occupation," "The Triple Pillar of Sino-Middle East Relations in the Age of Neoliberalism" (panel 4), "Trend of Turkish economic policy and the Sino-Turkish Economic Cooperation under the Presidential System", "China's 'Enmeshment' and the Middle East - a Theoretical Approach" (panel 5), "An analysis of China's Middle East Smart Power Strategy," "The Role of Infrastructure in the Middle East Economic Development and the Prospects of 'One Belt One Road"” (panel 6), "A Living Archive? Reflections on an Oral History Project with Palestinian Bedouin Women in the Naqab," and "China's Relations with Lebanon and Syria: a Comparative Analysis" (panel 7). Papers scheduled on the first day of proceedings were delivered by scholars representing universities with well-established traditions in the field in question, namely Chinese Academy of Social Sciences, Hamad bin Khalifa University, Harvard University, London School of Economics and Political Science, Middle East Technical University, Shanghai University, Texas Christian University, the University of Alberta, the University of California Santa Barbara, the University of Kassel, and the University of Sharjah.

The second day of the Conference consisted of nine panels. All of the presented papers were based on strong methodological foundations and reflected long-term research interests of the speakers. The ones that - according to the subjective opinion of the Author based on engagement and the questions provoked by the presentation - deserve recognition, were as follows:

- panel 8: "Turkish Foreign Policy and the Middle East: Opportunities and Challenges of Turkey in the Spiral of Power. Interests and Values," "Israel's Challenge of Stability in the Context of BRI's East Mediterranean Policies";

- panel 9: "China's Involvement in the Syrian Crisis: an Analysis of Beijing's UN Diplomacy," "Chinese Provinces as Foreign Policy Actors in the Middle East";

- panel 10: "Displacement of Global Power Balance: the China-USA-Iran Triangle as a Test Case";

- panel 11: "The Cyprus Question and the AKP Government (2002-2008)";

- panel 12: “The Dubai Silk Road Strategy: China's Evolving Role in the UAE's Development Trajectory", "China and the Reconstruction of Syria," "China's Energy Security Policy: from Malacca Dilemma to BRI";

- panel 13: "The Belt and Road Initiative and West Asia: Significance of Turkey-Iran Alliance," "A Geopolitical-Economic Perspective into the BRICS' Rise in Africa";

- panel 14: "The Changing Relationship between China and Russia in the Middle East";

- panel 15: "Importance of Youth, Entrepreneurship and Innovation on the Road and Belt Initiative".

Polish academic institutions were represented by scholars from Nicolaus Copernicus University in Torun and the University of Economics in Cracow, that is Dr. Magdalena Lewicka, Michał Dahl (panel 10, "Failed Strategy and Its Consequences: the Legacy of Barack Obama's Presidency in the Middle East") and Dr. Dobrosława Wiktor-Mach (panel 11, "Environmental Justice in Turkey: Conflicts and Responses") respectively. Similarly to the first day of the Conference, on May 18, all the papers were given by respected scholars affiliated with 
worldwide institutions, e.g. the Danish Institute for International Studies, Fudan University, Sichuan University, the University of Haifa, the University of Macao, the University of Michigan, the University of Oxford, and the University of Pennsylvania.

There is no doubt that the idea of organising an event dedicated to issues related to China, Middle East and mutual relations between these subjects is worthy and requires support. It seems to be even more beneficial, taking into consideration the international background of the invited speakers representing a whole variety of disciplines and research approaches. The abovementioned idea, together with an excellent organisation (thanks to Dr. Keskin, Dr. Yang, and numerous volunteers), constitutes a unique project that deserves appreciation. Likewise in the case of the previous editions, after the 5th China and the Middle East and North Africa Conference, a monographic collective work will be published. Selected papers will be placed in a peer-reviewed journal Sociology of Islam edited quarterly by Brill (Sociology of Islam). After the success of this year's edition, the organisers are already planning another meeting scheduled tentatively in May 2020, at one of the Middle Eastern partnering institutions.

Michał DAHL Toruń

\section{REFERENCES}

Call for papers: 5th China and The Middle East and North Africa Conference (2018, December 2), Institute of Global Studies, http://igse.shu.edu.cn/info/1011/1474.htm.

Sociology of Islam, Brill, https://brill.com/view/journals/soi/soi-overview.xml. 